DOI 10.37882/2223-2982.2020.04.11

\title{
ПРИРОДА ТРАГИЗМА ФИГУРЫ РОК-ГЕРОЯ КАК НОСИТЕЛЯ ВНУТРЕННЕГО КОНФЛИКТА
}

\section{THE NATURE OF THE TRAGEDY OF THE FIGURE OF A ROCK HERO AS A CARRIER OF INTERNAL CONFLICT}

\section{Doronin}

Summary: The article is devoted to the tragic side of nature of the figure of a rock hero, who is the subject of rock culture. Objectivity in this matter requires an analysis of both its positive and negative qualities. It is precisely on their marking and accentuation that its degree depends and without them its image will remain incomplete and undeveloped, to some extent losing its integrity and depth. This tragedy is not accidental and is due to several very specific and definite determinative foundations, which have their own nuances. Quite often, the conflicting side of his figure lies at the heart of the tragic and fatal character of the image of a rock hero. Therefore, the rock hero can be called a carrier of internal conflict. From which paradigms this conflict develops, which leads to this tragedy and this work is devoted to.

Keywords: rock culture; rock; rock hero; figure of a rock hero; fate; conflict; metaphysical rebellion; existence.

\author{
Доронин Владимир Викторович \\ К.ф.н., дочент, \\ Тюменский государственный университет \\ sibe1@rambler.ru
}

Аннотация: Статья посвящена трагичной стороне природы фигуры рокгероя, который является субъектом рок-культуры. Объективность в данном вопросе требует анализа как его положительных, так и отрицательных качеств. Именно от их маркирования и акцентуации зависит ее степень и без них его образ останется незавершенным и непроработанным, в какой-то степени потеряв свою целостность и глубину. Этот трагизм не случаен и обусловлен несколькими вполне конкретными и определенными детерминирующими основаниями, имеющими свои нюансы. Довольно часто в основе трагичного и фатального характера образа рок-героя лежит конфликтная сторона его фигуры. Поэтому рок-героя можно назвать носителем внутреннего конфликта. Из каких парадигм складывается эта конфликтность, что приводит к этому трагизму и посвящена данная работа.

Ключевые слова: рок-культура; рок; рок-герой; фигура рок-героя; судьба; конфликт; метафизический бунт; экзистенция.

ло слово. Потому что здесь было важнее - да и опаснее - выговориться... А рок всегда предрасположен к опасности». [3; С. 7] Но это всего один из немногих аспектов представляющий рок с протестной стороны. Автор же данной работы выстраивает категориальный аппарат и методологию с позиции философии, а в ней нет категории протеста. И протестную парадигму в рок-культуре с точки зрения философии нужно рассматривать через категорию бунта, в первую очередь метафизического и экзистенционального. Как писал А. Камю цель такого бунта - преображение. «Метафизический бунт - это восстание человека против своего удела и против всего мира, ...метафизический бунтарь протестует против удела, уготованного ему как представителю рода человеческого. Восставший раб утверждает, что в его душе есть нечто, не смиряющееся с тем, как обращается с ним господин; метафизический бунтарь заявляет, что он обделен и обделен самим мирозданием. Для обоих речь идет не только о простом отрицании. И действительно, и в том, и другом случаях мы сталкиваемся с суждением о ценности, во имя которой мятежник отказывается принять собственную участь». [2; С. 80] Другими словами, рок-герой через экзистинциональный страх, ужас, трепет и выведение из состояния комфорта, через психологическую неустойчивость приходит к недовольству своей судьбой, к несогласию и бунту против удела уготованного ею, следствием чего является потребность в ее 
изменении и стремление к внутреннему преображению.

Рассматривая причины конфликтной стороны природы рок-героя стоит упомянуть М. Фуко и его теорию конфликта «властных структур», которая являет собой демонстрацию власти через подавления и доминирования. Он писал следующее: «...там, где есть власть, есть и сопротивление, и все же, или скорее: именно поэтому сопротивление никогда не находится во внешнем положении по отношению к власти». [4; С. 195 - 196] В данном контексте рок-культура и является творчеством, которое может быть, вне социальных норм и табу, а разрушая эти рамки, может вступать в конфликт с институтом власти, становясь таким образом опасной для как отдельного индивида, для консервативной части общества, так и для власти в целом.

Что касается рок-героя, то он является целостной, многогранной сложносоставной фигурой, поэтому и его конфликтную сторону представляют различные аспекты. Одним из проявлений его сущностной природы является реализация его «роковой» судьбы, которая становится его экзистенцией и нередко являющей осуществление некой трагичной программы, вызванной рядом как закономерных, так и неподдающихся логике внутренних и внешних факторов и противоречий. Эта предрасположенность к фатализму, является одним из негативных качеств его природы, но при этом и одной из составных частей детерминирующего его основания. Отсюда происходит еще одна сторона конфликтности рок-героя - рассмотрение его фигуры как носителя внутреннего конфликта. В связи с этим мы одновременно будем рассуждать об экзистенции смерти или фатального стремления рок-героя к ней, предчувствии ее как неминуемой судьбы, но и при этом и о стремлении к противостоянию роковой судьбе и фатальной природы, которая заложена в нем. Это противоречие и становится одной из главных причин, делающими рок-героя носителем внутреннего конфликта. В разрез здравому смыслу, роковая судьба может являться положительным фактом в формировании фигуры рок-героя, так и в плане творчества. В этом и заключается один из парадоксов его фигуры, что чем ближе он подходит к этой трагичной черте, чем в нем больше фатального рокового, а не витального начала, тем чаще в нем раскрывается глубина его творческого потенциала. Перед лицом смерти, через фигуральный диалог с ней, с вечностью, с самим собой, с миром, с гипотетическим или конкретным слушателем, вообще через желание высказаться, рок-герой может дойти до осознания глубины природы вещей, его творчество может выйти на другой качественный уровень, в нем может появится новый всеобъемлюще емкий, точный и весомый посыл, отражающий точную суть событий и явлений. Смерть в таком случае может трактоваться как освобождение от ограничений, способ разрешения внутреннего конфликта, снятие противоречий, а суицидаль- ное поведение при этом может является своеобразным триггером, провоцирующим творческое вдохновение и озарения, являться своеобразным способом транцендирования рок-героя. Таким образом, он своим поведением, действиями, творчеством, утверждает, что заслуживает должного другого отношения по отношению к себе, что хочет большего, чем уготовано судьбой, поэтому старается ее изменить и преодолеть, даже ценой собственной жизни. Он становится «метафизическим бунтарем» реализующим свою героическую программу и в основе его внутреннего конфликта и лежит бунт метафизический. Альбер Камю полагал, что для человеческого духа вообще доступны только два универсума - священный универсум благодати и универсум бунта. «Бунт порождается осознанием увиденной бессмысленности, осознанием непонятного и несправедливого удела человека. Цель бунта - преображение». [2; С. 69] Бунт рокера - это и есть стремление к благодати, стремление к свободе, которая не доступна. Через попытку приблизиться к чему-то высшему, пусть даже вначале через его низвержение, он получает самоуважение, развивается и преображается.

Так же в основе конфликтной стороны и трагизма рок-героя еще зачастую лежит конфликт с вешним миром и связанным с ним усиливающимся внутренним одиночеством рок-героя. Этому могут сопутствовать различные факторы - непониманием окружающих его взглядов, действий, поступков, целей, жизненных принципов, отсутствие признания творчества, собственной неудовлетворенностью им и поиском его совершенства, нереализованным потенциалом, перфекционизмом т.д., а как итог неудовлетворенность в целом сложившимся положением дел. Рок-герой - это, в принципе, герой одиночка. Можно сказать, что он одинок изначально по своей природе и весь его Путь это именно череда испытаний, в том числе одиночеством, с которым он так же борется. Поэтому его одиночество это вследствие Агапе - безответной любви в глубоком духовном, философском и многих других смыслах.

Нужно отметить особо, что рок-герой по своему духу является героем новой формации. Именно современность, новые условия, в которых он оказывается, делают его таким. Причем, как раз одновременно «благодаря» и «вопреки» обстоятельствам рок-герой развивается и становится тем, кем должен стать. При всех своих положительных качествах, он часто непоследователен и нелогичен в своих действиях, нередко его поступки неоднозначны, необъяснимы, противоречивы и многим непонятны, не поддаются привычной логики и здравому смыслу. Для него нет авторитетов, он поступает против всех правил, выступает против всего и непохож на большинство других людей, пугая этим консервативную часть общества. Его отрицательная оценка всему - нигилизм в чистейшем виде. Как в песне у Егора Летова: «Я всегда 
буду против!» или «При любом Госстрое - я партизан». В этих коротких поэтических формулировках заложено очень много, что объясняет мотивы рок-героя в целом: его «Нет» - это и жизненное кредо, цель, установка и руководство кдействию. Эти действия часто действительно выгладят, как борьба Дон Кихота с ветреными мельницами. Рок-герой, как и его печальный предшественник, так же возмущен пороками общества и несовершенством окружающей его действительности, так же не вписывается в окружающий мир, неприспособлен к нему, чужд ему и инороден. Но это не показатель его слабости и бессилия, а, наоборот, в этом возможно главное его оружие. Он в принципе не умеет и не желает приспосабливаться и подстраиваться не под кого. Он не хочет мириться с не устраивающими его обстоятельствами жизни и принимать чужие правила игры. В его героической программе, в его посыле, экзистенции отсутствует приспособленчество и самосохранение. Эта функция, данная человеку от рождения, им сознательно «отключается», устраняется в процессе реализации его плана. Он настолько категоричен, что его категоричность, доведенная до радикализма, воспринимается окружающими как безумие. В обществе вообще всегда было принято объявлять безумным, ненормальным, то, что не понятно и проявлять агрессию по отношению к этому. Агрессия часто вызвана страхом непонимания. Под эти категории и попадает рок-герой. Его странность и непохожесть, вызывают непонимание, затем рождают страх и как следствие - агрессию по отношению к нему. Таким образом, картина мира, взгляды и логика рок-героя трактуются неправильно и попадают еще и под разряд безумия. Вследствие чего он отвергнут миром, а в свою очередь его ответной реакцией становится отвержение уже героем всего окружающего и как сопутствующий побочный результат - удвоенное одиночество и конфликт с окружающей реальностью. Помимо отвержения и отчуждения в нем рождается обида и в свою очередь ответная агрессия. И она вполне объяснима из выше сказанного. Рок-герой, несмотря на свою видимую внешнюю грозность, зачастую, как не странно, беззащитен перед окружающим миром. Его агрессия - ответная защитная реакцией, которая может проявляться и в эпатажном и шокирующем поведении различной степени. «Степень эпатажа» - термин, который постоянно употребляют, но обозначает он нечто гораздо более сложное: в основном это субъективная реакция с точки зрения потребителя. Подумайте о тех видах искусства, которые «шокировали». Человеческие реакции, положительные или отрицательные, не имеют для творца непосредственного значения. Тем не менее, принятие решений в процессе представления может быть направлено на создание определенного эффекта... Музыка создается потому, что я в нее верю, люблю ее и хочу слушать; она выражает мои интересы и все то, что имеет для меня значение... дух полностью свободной воли наполняет все аспекты моей работы». [5; С. 66] От- сюда агрессия и эпатаж и т.д - своеобразный панцирь, буфер между ранимым тонким духовным внутренним миром героя и равнодушным, жестоким, беспристрастным внешним миром окружающим. Рок-герой не просто неудобен для социума, он воспринимается как нарушитель спокойствие в обществе, саботирующим его четкую, отлаженную работу. И хотя на самом деле это далеко не всегда так, рок-герой видится для него источником опасности, которую нужно устранить и от которой нужно избавиться любыми способами. На лицо опять же «конфликт властных структур» по Фуко. Общество воспринимает рок-героя изгоем, маргиналом или он по собственному желанию выбирает этот удел и становится им. Так или иначе, напрямую или косвенно окружающий мир, несмотря на то, что поступает несправедливо по отношению к рок-герою «принимая радикальные меры», избавляется или уничтожает его или доводит до состояния самоуничтожения. Рок-герой же в свою очередь считает, что заслуживает другого к себе отношения, что он всегда хотел большего, чем уготовано судьбой, поэтому он старается ее изменить и преодолеть. Доведенный до крайности, он совершает отчаянные поступки, зная, что рассчитывать придется только на самого себя и собственные силы. Агрессия, таким образом, становится во многом положительной, как и его осознанная неприспособленность к окружающему миру - это не его слабость, а его сила, его плюс. Итогом этого конфликта является бунт как физический, так и метафизический, о котором и писал Альберт Камю. Пытаясь добиться поставленных целей, рок-герой вступает в конфликт как с самим собой, с окружающими, с обществом, с целым миром и мало того даже с Богом, при этом, полностью забывая о самом себе, и вполне очевидно, чем закончится для него это неравное противостояние. Пропасть между окружающим миром и героем увеличивается. Переступив через свое чувство самосохранения, он продолжает двигаться вперед «на зло и поперек», конфликт не разрешим, продолжает усугубляться и вследствие - неутешительный трагичный итог. Но, не смотря на это, рок-герой при этом не только теряет, но как не странно, он и многое обретает, пусть не в физическом смысле. Он остается самим собой и в высоком духовном смысле перерождается. Трагичный финал рок-героя - это его лебединая песня, жертва, искупление и одновременно утешение. Рок-герой подобен герою стихотворения Бродского:

«Может, лучшей и нету калитки в Ничто.

Человек мостовой, ты сказал бы, что лучшей не надо, Вниз по темной реке уплывая в бесцветном пальто,

Чьи застежки одни и спасали тебя от распада».

Трагизм, одиночество, агрессия героя - это и есть его внутренние скрепы, которые помогают сохранить и не растерять себя, но при этом дают возможность выйти за пределы ограничений. 
«Ты не дашь мне себя растерять, не дашь опуститься И прежде чем растворюсь в черной Дее могилы, Что бы я смог как феникс вновь возродиться, На ухо шепнешь: «Ничего не бойся,

Я буду с тобой до конца, милый!»

(Группа «СИстема БЕзопасности»)

Так мы приходим еще к одной стороне в образе рокгероя. Он непросто трагичен, он сознательно трагичен и иррационален, что в глазах окружающих приравнивается к безумию. Но его деструктивность по отношению к себе и к окружающему - не следствие природной мизантропии, так происходит в силу обостренного чувства справедливости и несовершенства окружающего мира. Он для него враждебен, его ценности не приемлемы, и вся внутренняя природа рок-героя протестует против этого. Он пытается уничтожить мир чуждых ценностей, как во внешних проявлениях, так и в себе. В виду неразрешимости этого противоречия, нередко выходом становится саморазрушение. Поэтому, как не печально рокгерою уготован яркий, но трагический финал. Его ждет, возможно красивый, но закономерный роковой, фатальный итог. В этом его судьба, его крест, одновременно победа и поражение, сила и слабость и в каком-то смысле это и есть его подвиг. Как в песне «Ванюша» Александра Башлачева: «Гулял Ванюша, да весь вышел».

Хотелось бы отметить, что трагичный образ фигуры рок-героя всегда связан с дуальностью. Этот двойной смысл заключается как в его природе, так и в его творчестве, только подтверждая его многоуровневый, сложный характер. Жизнь - Смерть, Любовь - Ненависть, Рай - Ад и т.д. Рок-герой всегда выбирает только крайности, он не приемлет середины, категоричен, бескомпромиссен радикален и пограничен, он всегда трикстер. Опять же, как в другой песне у Егора Летова:

«Но мне придется выбирать -

Свет или Больше,

Рай или Больше,

Смерть или Больше...».

Поэтому, через конфликт, через усугубление, обострение ситуации, через пограничность как физического, так и внутреннего психического и эмоционального состояния, происходит выход за пределы и ограничения. Происходит понимание и осознание героем окружающего мира, самого себя, своего предназначения на новом более высоком уровне и результате чего осуществляется реализация его героического потенциала. В возможности выбора между этими полярностями для рок-героя состоит еще один способ получения свободы, а в доведении всего до крайности, видится раздвижение границ его мира внутреннего, ойкуменальности бытия, возведение всего в новую качественную степень. Поэтому даже смерть для него имеет тоже двоякий смысл, так как, отдавая жизнь, рок-герой при этом борется против своей конечной смертной природы. Его гибель является платой за его ненасытность свободой, творческую жажду и голод, платой за талант, а жизнь героя становится страшной ценой, которую рано или поздно все равно надо, придется заплатить. В этом и состоит трагизм образа рок-героя. Он одинок, неудобен, проблемен, «ненормален» и «безумен» в глазах общества и окружающих. И они уничтожают таких одиночек. Как в песне Ника Рокн-ролла:

«В традициях мира убивать святых,

В традициях мира убивать поэтов.

В традициях мира покоится Мень,

В традициях мира покоится жизнь».

Настоящие герои никогда не вписываются в рамки и стереотипы, они не подходят ни под какие стандарты и общепринятые схемы, каждый такой герой - индивидуальность. Противоречие между героем и внешним миром вряд ли будет когда-то разрешимо. Этим во многом объясняется и столь часто суицидальное поведение в рок-культуре. В этом контексте гибель героя воспринимается им самим, хоть, как и печальный, закономерный, но в чем-то, как не страшно это звучит, положительный факт и итог. Это и некий катарсис, и плата, и искупление. В гибели рок-героя, то же есть некое прочувствование, дыхание вечности. Для высоко организованного разума, как бы страшно бы это не звучало, «смерть - это очередное приключение». Это последняя, отчаянных, страшная попытка, возможность заглянуть за занавес, выти за флажки, раздвинуть границы, рамки и ограничения, узнать, что же находиться за ними. Цена этого знания жизнь. В этом смысле, самоубийство так же не всегда может трактоваться как проявление слабости и бессилия, а как радикальный способ трансцендирования героя. Поэтому трагизм и конфликтная сторона фигуры рокгероя - это законы жанра, через которые раскрываются его внутренние сущностные качества. Рок-герой доказывая свою правоту, требуя справедливости и изменения мира, жертвует подобно Прометею своей собственной жизнью. И эта жертва в принципе практически бескорыстна. Несмотря на это, в обществе существует весьма искаженный стереотип рок-музыканта. Конфликтную сторону и трагизм фигуры рок-героя, по субъективному и весьма далекому от истины мнению противников рока, усиливают пресловутые секс, алкоголь и наркотики, как якобы его «неотъемлемые» попутчики. Это далеко не так, для него они являются не самоцелью, а часто необходимостью, средством, «трамплином» для возведения всего в новую степень, выходом за границы и способом поиска новых творческих пространств и в тоже время еще один способ, метод заполнение страшной внутренней пустоты и одиночества и познания пограничных сторон бытия. Это нелегальный, запретный, табуированный и опасный метод достижения трансцендентного опыта. Мы несколько не хотим оправдать их, но все эти «из- 
лишества» - несомненно, страшные, не самые лучшие, но тем не менее своеобразные и радикальные способы трансцендирования рок-героя - опыт темных антологический, так же необходимый, для последующего его преображения и возможно без которого тоже нельзя, потому что как любая другая культура - рок-культура является совокупностью положительных и отрицательных составляющих ее качеств и элементов. Являясь одними из болезней современного общества, они, к сожалению, не миновала и рок-культуру. Константин Кинчев из группы «Алиса» спел: «Все это рок-н-ролл...». Как бы не печально и цинично не звучало, все выше изложенное и трагизм, в том числе - издержки «производства», законы жанра, чтоб рок-герой состоялся в полной мере, этого требует и ждет публика. Об этом знает и он сам, осознавая свое предназначение и на рок-герое лежит большая ответственность, в том числе и за талант, как дар свыше, который делает его особенным и уникальным. Это все требует от героя больших физических и внутренних духовных затрат. Не всем суждено пройти все испытания и только единицы достигают признания, не потеряв себя и оставшись живыми, приходят к внешнему и духовному преображению. В целом это все в очередной раз только подчеркивает архетипичность и вневременной характер фигуры рок-героя.

У Виктора Цоя есть в одной из песен есть следующие строчки:
«И мы знаем, что так было всегда,

Кто судьбою больше любим,

Кто живет по законам другим

И кому умирать молодым.

Он не знает ни чинов, не имен.

И способен дотянуться до звезд,

Не считая, что это сон.

И упасть, опаленным звездой по имени Солнце».

В заключении статьи резюмируем следующее. Рокгерой - это современный герой нашего времени, фигура, которого, несомненно, сложна, как и его путь. Она несет в себе трагичные черты, но вместе с этим этот харизматичный образ бескорыстен, романтичен, ярок и альтруистичен, этим он привлекателен и вызывает интерес. В классической литературе таких неоднозначных героев называли - носителями внутреннего конфликта, который в свою очередь является одним из детерминирующих его оснований. Иногда этот конфликт и противоречия становятся не разрешимы и приводят к трагическому итогу. Несмотря на отдельные негативные качества, в целом этот герой положительный. Нередко забывая о самосохранении, через сопротивление трудностям и обстоятельствам, через преодоление пограничных состояний, через преодоление ограничений внутренних и внешних, происходит становление, развитие личности и преображение рок-героя.

\section{ЛИТЕРАТУРА}

1. Доронин В.В. Рок-культура как современное воплощение традиции героев: монография / В. В. Доронин. - Тюмень: Издательство Тюменского университета, 2017. - 268 c.

2. Камю А. Бунтующий человек: сочинения в 5 т.: т 3 / А. Камю. - Харьков: Фолио, 1998. - 574 с.

3. Троицкий А. Рок в Союзе: 60-е, 70-е, 80-е ... / А. Троицкий. - М.: Искусство, 1991. - 206 с.

4. Фуко М. Воля к истине: по ту сторону знания, власти и сексуальности. Работы разных лет. Пер. с франц.- М.: Касталь, 1996. - 448 с.

5. Keenan D.A secret History of the Esoteric Underground. Strange Attractor Press. BM SAP, London, WCIN 3XX, UK, 2016. - 446 p.

(c Доронин Владимир Викторович (sibe1@rambler.ru). 